\title{
BMJ Open Predictors of quality of life 1 year after minor stroke or TIA: a prospective single-centre cohort study
}

\author{
Ka-Hoo Lam (D) , Emma Blom (D) , Vincent I H Kwa (D)
}

To cite: Lam K-H, Blom E, Kwa VIH. Predictors of quality of life 1 year after minor stroke or TIA: a prospective singlecentre cohort study. BMJ Open 2019;9:e029697. doi:10.1136/ bmjopen-2019-029697

- Prepublication history for this paper is available online. To view these files, please visit the journal online (http://dx.doi.org/ 10.1136bmjopen-2019-029697)

$\mathrm{K}-\mathrm{HL}$ and $\mathrm{EB}$ contributed equally.

Received 06 February 2019

Revised 05 July 2019

Accepted 03 October 2019

\section{Check for updates}

(C) Author(s) (or their employer(s)) 2019. Re-use permitted under CC BY-NC. No commercial re-use. See rights and permissions. Published by BMJ.

Department of Neurology, OLVG, Amsterdam, Netherlands

Correspondence to Dr Vincent I H Kwa; v.i.h.kwa@olvg.nl

\section{ABSTRACT}

Objectives In patients after a transient ischaemic attack (TIA) or minor stroke, dysfunction is often underestimated by clinical measures due to invisible symptoms, including cognitive and emotional problems. Many of these patients need stroke care programme, but others do not. In this study, we aim to identify potential predictors of quality of life $(\mathrm{Q} \mathrm{L}$ ) in patients with TIA or minor stroke 1 year poststroke to be able to select which of these patients will need aftercare.

Design Prospective observational cohort study.

Setting Single-centre hospital in the Netherlands.

Participants 120 patients, diagnosed with TIA or minor stroke and discharged without rehabilitation treatment, completed the study.

Primary and secondary outcome measures QoL (RAND-36), anxiety and depressive symptoms (Hospital Anxiety and Depression scale), the degree of disability or functional dependence after stroke (modified Rankin Scale (mRS)) and symptoms of anxiety and depression specific to stroke (SSADQ) were assessed at baseline (2-6 weeks poststroke) and compared with follow-up at 1 year poststroke.

Results Depression $(B=-1.35, p<0.001)$ and anxiety $(B=-0.57, p=0.041)$ at baseline predicted a worse mental component of $Q \mathrm{LL}$ after 1 year. Depression $(B=-1.100$, $p<0.001)$ at baseline, but also age $(B=-0.261, p=0.002)$ and female sex $(B=4.101, p=0.034)$ predicted a worse physical component of QoL after 1 year.

Conclusion With the identification of these predictors, we might be able to select more efficiently and timely the patients with TIA or minor stroke who need stroke aftercare.

\section{INTRODUCTION}

Although mortality rates have declined, the incidence of ischaemic stroke has remained stable or even increased slightly. ${ }^{1}$ As a consequence of stroke, many patients experience persistent deficits and reduced functional independence. ${ }^{2}$ According to a recent report from the Global Burden of Disease (GBD) 2016 Lifetime Risk of Stroke Collaborators, cerebrovascular disease ranks second in leading causes of disability-adjusted life years globally, with the burden of disease increasing proportionally to age and in the more developed regions. ${ }^{3}$ Based on severity

\section{Strengths and limitations of this study}

In this prospective study, potential predictors of quality of life were included after thorough consideration based on previous research.

- The sample size of the study was calculated based on the number of predictors.

- A considerable part of our study population of patients who suffered a transient ischaemic attack or minor stroke was excluded due to several reasons, but no differences were found in patient characteristics between the study population and the excluded patients.

- During follow-up, there was no insight into outpatient rehabilitation care, changes in medication or employment.

and duration, ischaemic stroke can be classified as major and minor stroke and transient ischaemic attack (TIA). ${ }^{45}$

Patients with major stroke and severe debilitating symptoms usually receive further rehabilitation treatment. $^{2}$ In contrast, full recovery is assumed in patients with minor stroke or TIA, and these 'walking and talking' patients are discharged home from the hospital without rehabilitation. ${ }^{6}$ However, previous studies found that a substantial proportion of these patients do suffer from invisible symptoms, including cognitive and emotional problems. ${ }^{6-13}$ When assessment only includes clinical measures such as the modified Rankin Scale (mRS), these problems can easily be overlooked. Nevertheless, these complaints can be a major contributor to poor quality of life (QoL).$^{6-8}$ In the past few years, this problem has been addressed by the introduction of many outpatient stroke care programmes targeting patients with minor stroke or TIA. Evidence is accumulating that these outpatient stroke care programmes may improve QoL and self-efficacy 3-12 months poststroke. ${ }^{1415}$ However, a significant group of patients without residual signs or symptoms do not need this aftercare. The scarce resources and time of healthcare professionals 
in stroke could, therefore, be spend more efficiently by only giving the stroke care programme to patients who really need this. In terms of costs, it would be efficient to be able to select which patients might need care and who do not. Little is known about which factors might predict invisible symptoms after 1 year. This study aims to identify potential predictors associated with a lower QoL 1 year after the stroke to be able to select which 'walking and talking' patients will need aftercare.

\section{METHODS}

\section{Study design}

From January 2016 to May 2018 at OLVG Oost hospital, medical records of patients admitted with TIA or minor stroke 1 year ago were screened for participation in this prospective cohort study. TIA and minor stroke were defined as acute neurological deficits that fully resolve within 24 hours and 3 days, respectively, followed by discharge from the hospital without the need for rehabilitation treatment. These patients had a mRS of $<2$ (see the Health outcomes section). As part of standard clinical care, patients with TIA and stroke discharged to home are re-evaluated by a specialised stroke nurse shortly after discharge. All patients with residual or new symptoms are referred to the Beroerte Adviescentrum (BAC), a Stroke Advice Centre in Amsterdam for further outpatient care where health outcomes are assessed at baseline (i.e., shortly after the TIA or stroke). The $\mathrm{BAC}$ is a service in Amsterdam run by nurses to support patients discharged home after stroke to improve independence and self-rehabilitation. Because patients can only participate in this study when baseline assessments were completed, patients who were not referred to BAC or did not complete baseline assessments were excluded. Furthermore, patients were excluded if below 18 years of age, if insufficiently proficient in Dutch or if they had dementia or behavioural disorders compromising study participation. The study received full ethical approval and all included patients gave written consent.

\section{Participants}

Eligible patients were initially contacted by telephone. Following verbal consent, paper study materials were sent by mail and included study information, consent form, forms for assessing health status at 1 year poststroke and a form for obtaining sociodemographic information. After written consent and the completed study forms were returned, a telephone-based assessment of the mRS was done. Additional clinical data were collected from medical records. Baseline health status was assessed 1 year prior as part of standard clinical care (figure 1).

\section{Patient and public involvement}

The aim and objective of this study have been based on the need for better patient-tailored aftercare for patients with TIA or minor stroke. As experiences of patients who had a TIA or minor stroke and previous research in stroke care

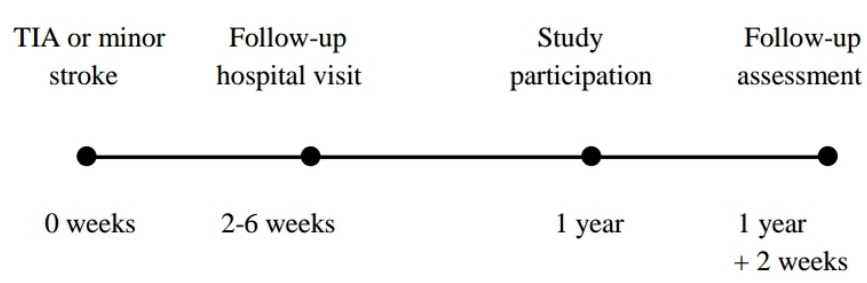

Figure 1 Flowchart of the study.

revealed unrecognised symptoms and burden of disease, earlier and improved identification of patients 'at risk' could be beneficial for the long-term QoL after stroke. However, we did not involve patients or patient advisers in the design, recruitment or conduct of the study. In our study, all health outcomes were completed on paper surveys at home, and structured telephone interviews. Participants were easily accessible by telephone allowing better recruitment and participation rates. The results of this study will be disseminated to all study participants by letter at the end of the study, as stated in the informed consent form.

\section{Health outcomes}

Health outcomes were assessed at baseline as part of standard clinical practice and 1 year poststroke (follow-up) as part of this study. QoL was assessed with the research and development-36 scale (RAND-36), one of the most widely used health-related quality of life (HRQoL) survey instruments in stroke. ${ }^{16}{ }^{17}$ It comprises 36 items, assessing the following health domains: physical functioning, social functioning, role limitations due to physical problems, role limitations due to mental problems, mental health, vitality, bodily pain, fatigue, general health and health change. These domains can be scored into scale scores, from which two summary scores can be derived: a physical (PCS) and a mental (MCS) component score. The scores range from 0 to 100 , with higher scores reflecting better outcome. The RAND-36 has been translated and validated into multiple languages, including Dutch. The minimal clinically important difference (MCID) for the RAND-36 is in the range of 3-5 points. ${ }^{17}$ In this study, the Dutch RAND-36 V.2 was used.

Depression and anxiety were assessed with the Hospital Anxiety and Depression Scale (HADS), an extensively researched and validated scale for the measurement of anxiety and depression. ${ }^{18}$ The HADS consists of 14 questions graded on a 4-point rating scale. Subsequently two subscales, anxiety (seven items) and depression (seven items), can be calculated by summing their respective items. A score between 7 and 10 suggests probable anxiety or depressive disorder, whereas a score of 11 or higher is indicative of an anxiety or depressive disorder. The MCID for the HADS in patients with cardiovascular disease is 1.7 points. ${ }^{19}$ In addition, the Stroke-Specific Anxiety and Depression Questionnaire (SSADQ), developed by neuropsychologists for the assessment of symptoms of anxiety and depression specific to stroke, was assessed. This questionnaire, although not validated, was thought to be more sensitive than the HADS in this stroke population. 
The degree of disability or functional dependence after stroke was assessed with the mRS, an outcome measurement scale ranging from 0 (no limitations or symptoms in activities of daily living) to 5 (bedridden) and 6 (death). The mRS is also shown to be reliably assessed through telephone interviews. ${ }^{20}$ Baseline mRS was assessed in person by one of three stroke nurses of the BAC at 3 months postevent. Follow-up mRS was assessed through a semistructured telephone interview by one of four researchers, who all completed an online video-based training developed by Quinn et al. ${ }^{21}{ }^{22}$ Sociodemographic characteristics collected at follow-up were: marital status (married, unmarried or widowed); level of education, assessed on a Dutch 7-point scale (Schaal van Verhage) and afterwards stratified into three groups: low (1-2), average (3-5), high (6-7); current living arrangement (alone or with spouse/ relative(s)); recurrence of TIA, ischaemic or haemorrhagic stroke during the period between onset of stroke and follow-up.

\section{Statistical analysis}

Mean, median and the visual inspection of histograms and P-P plots were used to assess whether or not the data were normally distributed. Independent samples $t$-test and $\chi^{2}$ test were used for assessing differences in patient characteristics. Changes between baseline and follow-up health outcomes were assessed using paired samples $t$ tests and Wilcoxon signed-rank tests for data distributed normally and non-normally, respectively. Multiple linear regression analysis was performed for the identification of predictors of QoL, using a stepwise backward elimination method with a p-value of $>0.10$ set as the threshold for elimination. ${ }^{23}$ For the remaining analyses, a p-value of $<0.05$ was considered to be statistically significant. The following 12 predictors were entered at the beginning of the analysis: marital status, HADS depression score, HADS anxiety score, SSADQ score, recurrence of TIA or minor stroke, living arrangement, level of education, age, sex, mRS score, incidence, location of TIA or minor stroke. These predictors have been carefully selected based on previous research. ${ }^{24-29}$ Given that marital status and degree of education were categorical variables, dummy variables were used in this analysis. Variance inflation factor (VIF) and tolerance diagnostics were checked to assess multicollinearity. The sample size was determined with a minimum of 10 participants needed per predictor variable. With 12 potential predictors to be tested, the sample size was set at 120 participants. ${ }^{23}$ The pairwise deletion was used with regard to the missing values.

All statistical analyses were performed using IBM SPSS V.22.0.0.1.

\section{RESULTS}

Between December 2014 and July 2017, 370 eligible patients were identified. A total of 157 were excluded as baseline health outcomes were missing, 36 refused participation, 19 did not return the follow-up questionnaires,
14 were insufficient proficient in Dutch, 13 died, 6 were excluded due to behavioural disorders, and 5 were not reachable by phone. The patient characteristics of both the study population and excluded patients are summarised in table 1 . There were no statistically significant differences between the study population and the excluded patients. With the use of pairwise deletion for missing values, the variables HADS depression score, MCS and PCS had one participant with missing data, HADS anxiety score had two participants with missing data and mRS baseline score had 38 participants with missing data. The average number of days between the stroke date and the follow-up date was slightly higher than planned, $(M=379.3$ days, $\mathrm{SD}=47.1)$.

The mRS was slightly higher after 1 year without reaching statistical significance as compared with baseline. The SSADQ score however, was statistically significantly better after 1 year. The RAND-36 subscales 'role limitations due to physical problems', 'role limitations due to mental problems', and 'health change' were statistically significantly higher than baseline scores, reaching the range of 3-5 points for a minimally clinically important difference (tables 2 and 3 and figure 2).

\section{Predictors of QoL}

Mental component

For the mental component of the RAND-36, we found two predictors that explained $39.8 \%$ of the variance, with $R^{2}=0.398, R^{2}$ adjusted $=0.387$ and $F=37.638(2,114)$ $(p<0.001)$. The results are summarised in table 4 .

\section{Physical component}

For the physical component of the RAND-36, we found three predictors explaining $26.1 \%$ of the variance, with $R^{2}=0.261, \quad R^{2}$ adjusted $=0.241$ and $F=13.392 \quad(3,114)$ $(\mathrm{p}<0.001)$. The results are summarised in table 4 .

\section{DISCUSSION}

In this study, we found that depression and anxiety at baseline predicted a worse mental component of QoL after 1 year as measured with the RAND-36 in patients discharged home after a TIA or minor stroke. Depression at baseline, but also age and being a woman, predicted a worse physical component of QoL after 1 year. These findings might be important for selecting patients for interventions to prevent unforeseen problems long after their TIA or minor stroke.

In these patients, we also found a slight improvement of QoL after 1 year as measured with the RAND-36, without being clinically significant. Van Mierlo $e t$ al also reported modest improvements in QoL in a population with more severe stroke patients, but mostly in the first 6 months after onset and more pronounced in activities of daily life(ADL)-independent patients. ${ }^{24}$ Our study confirms that in ADL-independent patients after stroke, the QoL also improves within 1 year, but less obvious than in the previous study. We think that this is a reflection of coping 
Table 1 Comparison of patient characteristics of the study population and the excluded patients

\begin{tabular}{|c|c|c|c|}
\hline Characteristic & $\mathrm{N}=120$ & Excluded patients $(\mathrm{N}=250)$ & $P$ value \\
\hline Age, y, mean (SD) & $68.6(11.5)$ & $68.4(12.1)$ & $0.891^{*}$ \\
\hline Sex & & & $0.155 \dagger$ \\
\hline Female & $43(35.8)$ & $109(43.6)$ & \\
\hline Male & $77(64.2)$ & $141(56.4)$ & \\
\hline Diagnosis & & & $0.360 \dagger$ \\
\hline TIA & $29(24.2)$ & $50(20.0)$ & \\
\hline Minor stroke & $91(75.8)$ & $200(80.0)$ & \\
\hline Localisation & & & $0.508 \ddagger$ \\
\hline Right hemisphere & $31(25.8)$ & 75 (30.0) & \\
\hline Left hemisphere & $55(45.8)$ & $101(40.4)$ & \\
\hline Vertebrobasilar & $30(25.0)$ & $56(22.4)$ & \\
\hline Ocular & $0(0.0)$ & $3(1.2)$ & \\
\hline Other & $4(3.3)$ & $15(6.0)$ & \\
\hline Stroke incidence & & & $0.267 \dagger$ \\
\hline Relapse & $20(16.7)$ & $54(21.6)$ & \\
\hline First ever & $100(83.3)$ & $196(78.4)$ & \\
\hline Marital status & & $\mathrm{n} / \mathrm{a}$ & \\
\hline Married & $61(50.8)$ & & \\
\hline Unmarried & $44(36.7)$ & & \\
\hline Widowed & $15(12.5)$ & & \\
\hline Education & & $\mathrm{n} / \mathrm{a}$ & \\
\hline Low & $12(10.0)$ & & \\
\hline Average & $58(48.3)$ & & \\
\hline High & $49(40.8)$ & & \\
\hline Living arrangement & & $\mathrm{n} / \mathrm{a}$ & \\
\hline Alone & $51(42.5)$ & & \\
\hline With spouse/relative(s) & $68(56.7)$ & & \\
\hline
\end{tabular}

All data are expressed as $n(\%)$, except where specified.

${ }^{*} t$-test

$\dagger \chi^{2}$ test

$\ddagger$ Fisher exact test

TIA, transient ischaemic attack.

mechanisms in the chronic phase when patients still have handicaps of problems after their stroke or TIA.

In this study, we found four predictors for a lower QoL after 1 year, but depression was the only one that was significant in both domains of QoL. The more symptoms of depression, as measured with the HADS at baseline, the worse the mental and physical component of QoL was after 1 year. Depression at baseline is frequently seen in patients who suffered from a stroke. ${ }^{25}$ A review estimated that one third of stroke survivors suffered from depression at any time up to 5 years after stroke. ${ }^{26}$ The finding that depression at baseline is a predictor for worse QoL after a TIA or minor stroke was well in line with a previous study, that showed that poststroke depression in the acute phase after stroke predicts worse QoL, 1 year after TIA or minor stroke. ${ }^{27}$ Another study found that poststroke depression

Table 2 SSADQ and MRS scores at baseline and follow-up (paired samples $t$-test)

\begin{tabular}{|c|c|c|c|c|c|c|c|}
\hline & \multicolumn{2}{|l|}{ Baseline } & \multicolumn{2}{|l|}{ Follow-up } & \multirow[b]{2}{*}{$95 \% \mathrm{Cl}$} & \multirow[b]{2}{*}{$t$-value (df) } & \multirow[b]{2}{*}{$P$ value } \\
\hline & Mean (SD) & $\mathbf{N}$ & Mean (SD) & $\mathbf{N}$ & & & \\
\hline SSADQ score & $17.1(8.3)$ & 90 & $13.5(8.3)$ & 90 & 2.119 to 5.037 & $4.87(89)$ & $<0.001$ \\
\hline mRS score & $1.0(0.8)$ & 77 & $1.2(0.9)$ & 77 & -0.372 to 0.009 & $-1.90(76)$ & 0.061 \\
\hline
\end{tabular}

SSADQ, Stroke-Specific Anxiety Depression Questionnaire; mRS, modified Rankin Scale. 
Table 3 HADS and RAND-36 scores at baseline and follow-up (Wilcoxon signed-rank test)

\begin{tabular}{|c|c|c|c|c|c|c|}
\hline & \multicolumn{2}{|l|}{ Baseline } & \multicolumn{2}{|l|}{ Follow-up } & \multirow[b]{2}{*}{ Z-score } & \multirow[b]{2}{*}{$P$ value } \\
\hline & Mean (SD) & $\mathbf{N}$ & Mean (SD) & $\mathbf{N}$ & & \\
\hline HADS depression & $4.3(4.1)$ & 119 & $4.2(4.1)$ & 119 & -0.759 & 0.448 \\
\hline RAND-36 physical component & $44.8(10.2)$ & 116 & $45.0(11.4)$ & 119 & -1.225 & 0.221 \\
\hline RAND-36 mental component & $46.1(11.1)$ & 116 & $47.7(11.1)$ & 119 & -1.451 & 0.147 \\
\hline
\end{tabular}

HADS, Hospital Anxiety Depression Scale; RAND-36, Reseach and Development-36 scale.

has a high association with disability and poor QoL 1 year after minor stroke. ${ }^{28}$ We think that early depressive symptoms might be a criterion in our patients to select the ones who need aftercare soon after their TIA or minor stroke.

The anxiety scale of the HADS was found to be a predictor for a worse mental component and not for a worse physical component of the RAND-36. Previous research also found that poststroke anxiety is less important than poststroke depression as a predictor for QoL. ${ }^{29}$ Nevertheless, an association was found in several studies between poststroke anxiety and QoL $^{29-32}$ and anxiety early after TIA or minor stroke might also be a reason to offer more active stroke aftercare.

In our study, women have a lower physical QoL after stroke, in comparison with men. This result is in line with previous studies that found that women have worse HRQoL after stroke, in comparison with men. ${ }^{33} 34 \mathrm{~A}$ higher prevalence of disability and a greater age at stroke onset in women could be a possible explanation for this finding. ${ }^{35}$ It is important to realise that in previous research in the general population, women had worse HRQoL compared with men even without having a disease. ${ }^{36}$ However, socioeconomic status and sociodemographic characteristics such as race and education might be an explanation for the differences in that study. Age itself was found to be a predictor for physical QoL. This is also in line with another study that stated that as the

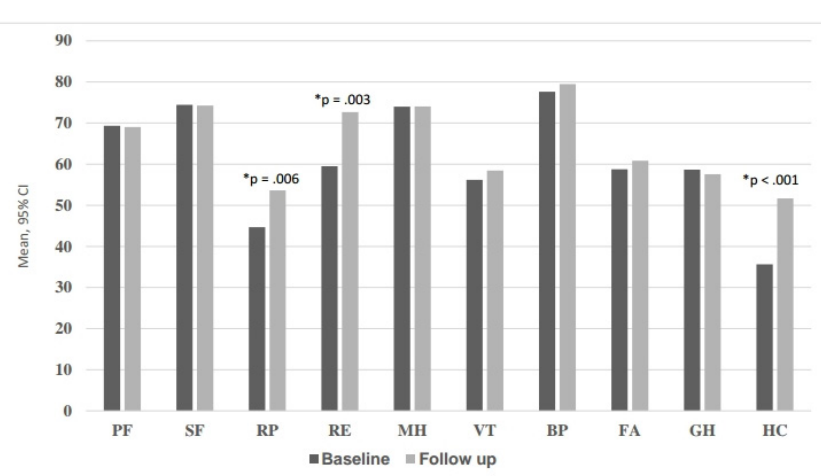

Figure 2 Bar graph of RAND-36 subscale scores at baseline and follow-up. BP, bodily pain; FA, fatigue; $\mathrm{GH}$, general health; $\mathrm{HC}$, health change; $\mathrm{MH}$, mental health; $\mathrm{PF}$, physical functioning; RE, role limitations due to mental problems; $\mathrm{RP}$, role limitations due to physical problems; SF, social functioning; VT, vitality. ${ }^{\star}$ Statistically significant difference.

\begin{tabular}{|c|c|c|c|c|c|}
\hline & B & SE & $\beta$ & $t$-value & P value \\
\hline \multicolumn{6}{|l|}{ Mental component } \\
\hline Constant & 56.14 & 1.32 & & 42.52 & $<0.001$ \\
\hline HADS depression & -1.35 & 0.25 & -0.5 & -5.47 & $<0.001$ \\
\hline HADS anxiety & -0.57 & 0.28 & -0.19 & -2.07 & 0.041 \\
\hline \multicolumn{6}{|l|}{ Physical component } \\
\hline Constant & 65.13 & 6.1 & & 10.67 & $<0.001$ \\
\hline Age & -0.26 & 0.08 & -0.27 & -3.25 & 0.002 \\
\hline Sex & 4.1 & 1.92 & 0.18 & 2.14 & 0.034 \\
\hline HADS depression & -1.1 & 0.23 & -0.4 & -4.9 & $<0.001$ \\
\hline
\end{tabular}

HADS, Hospital Anxiety Depression Scale; QoL, quality of life.

population ages, the number of strokes and therefore stroke survivors with poor QoL increases. ${ }^{37}$

The strength of our study is the prospective nature of our cohort in which possible predictors have been included that have been carefully selected based on previous research. A limitation of this study is the fact that a substantial part of our study population of patients who suffered a TIA or minor stroke was excluded due to several reasons. However, there were no differences in patient characteristics between the study population and the excluded patients. Another limitation is that during the year between baseline and follow-up, there was no insight into outpatient rehabilitation care, changes in medication or employment.

\section{Conclusions}

In this study, we found that baseline depression and anxiety predicted worse mental QoL, whereas baseline depression, age and sex predicted worse physical QoL. With the identification of these predictors, we might be able to select more efficiently and timely the patients with TIA or minor stroke who need stroke aftercare.

Acknowledgements The authors would like to thank all patients that have participated in this study. The authors would also like to thank M Lagerwaard, C Brands and the BAC team: I Bekker, J Kramer and B Notz, for their efforts in the data collection, and $D$ van Rooijen for providing support in statistical analysis.

Contributors VIHK: designed the work and had substantial contributions to the acquisition, analysis, and interpretation of data, in drafting the work and revising it critically for important intellectual content, and gave final approval of the version to 
be published, and agreed to be accountable for all aspects of the work in ensuring that questions related to the accuracy or integrity of any part of the work are appropriately investigated and resolved. EB: gave substantial contributions to the acquisition, analysis, and interpretation of data, in drafting the work and revising it critically for important intellectual content, and gave final approval of the version to be published, and agreed to be accountable for all aspects of the work in ensuring that questions related to the accuracy or integrity of any part of the work are appropriately investigated and resolved. K-HL: gave substantial contributions to the acquisition, analysis, and interpretation of data, in drafting the work and revising it critically for important intellectual content, and gave final approval of the version to be published, and agreed to be accountable for all aspects of the work in ensuring that questions related to the accuracy or integrity of any part of the work are appropriately investigated and resolved. EB and K-HL: contributed equally to this work. All authors have confidence in the integrity of each other's contributions.

Funding This research is funded by the Foundation Teaching Hospital OLVG, Amsterdam.

\section{Competing interests None declared.}

Patient consent for publication Not required.

Ethics approval Medical research Ethics committees United. Research Ethics number: W0 16.560

Provenance and peer review Not commissioned; externally peer reviewed.

Data availability statement Data are available upon reasonable request.

Open access This is an open access article distributed in accordance with the Creative Commons Attribution Non Commercial (CC BY-NC 4.0) license, which permits others to distribute, remix, adapt, build upon this work non-commercially, and license their derivative works on different terms, provided the original work is properly cited, appropriate credit is given, any changes made indicated, and the use is non-commercial. See: http://creativecommons.org/licenses/by-nc/4.0/.

\section{ORCID iDs}

Ka-Hoo Lam http://orcid.org/0000-0003-0926-1445

Emma Blom http://orcid.org/0000-0003-0565-2983

Vincent I H Kwa http://orcid.org/0000-0002-0942-6206

\section{REFERENCES}

1 Vaartjes I, O'Flaherty M, Capewell S, et al. Remarkable decline in ischemic stroke mortality is not matched by changes in incidence. Stroke 2013;44:591-7.

2 Winstein CJ, Stein J, Arena R, et al. Guidelines for adult stroke rehabilitation and recovery. Stroke 2016;47:98-169.

3 Feigin VL, Nichols E, Alam T, et al. Global, regional, and national burden of neurological disorders, 1990-2016: a systematic analysis for the global burden of disease study 2016. Lancet Neurol 2019:18:459-80.

4 Fischer U, Baumgartner A, Arnold M, et al. What is a minor stroke? Stroke 2010;41:661-6.

5 Easton JD, Saver JL, Albers GW, et al. Definition and evaluation of transient ischemic attack. Stroke 2009;40:2276-93.

6 Edwards DF, Hahn M, Baum C, et al. The impact of mild stroke on meaningful activity and life satisfaction. J Stroke Cerebrovasc Dis 2006;15:151-7

7 Duncan PW, Samsa GP, Weinberger M, et al. Health status of individuals with mild stroke. Stroke 1997;28:740-5.

8 Suenkeler IH, Nowak M, Misselwitz B, et al. Timecourse of healthrelated quality of life as determined 3, 6 and 12 months after stroke. Relationship to neurological deficit, disability and depression. $J$ Neurol 2002;249:1160-7.

9 Arts MLJ, Kwa VIH, Dahmen R. High satisfaction with an individualised stroke care programme after hospitalisation of patients with a TIA or minor stroke: a pilot study. Cerebrovasc Dis 2008;25:566-71.

10 Muus I, Petzold M, Ringsberg KC. Health-related quality of life among Danish patients 3 and 12 months after TIA or mild stroke. Scand J Caring Sci 2010;24:211-8.

11 Verbraak ME, Hoeksma AF, Lindeboom R, et al. Subtle problems in activities of daily living after a transient ischemic attack or an apparently fully recovered non-disabling stroke. J Stroke Cerebrovasc Dis 2012;21:124-30.

12 Radman N, Staub F, Aboulafia-Brakha T, et al. Poststroke fatigue following minor infarcts: a prospective study. Neurology 2012;79:1422-7.
13 Moran GM, Fletcher B, Feltham MG, et al. Fatigue, psychological and cognitive impairment following transient ischaemic attack and minor stroke: a systematic review. Eur J Neurol 2014;21:1258-67.

14 Fryer CE, Luker JA, McDonnell MN, et al. Self management programmes for quality of life in people with stroke. Cochrane Database Syst Rev 2016:CD010442.

15 Fu V, Weatherall M, McPherson K, et al. Taking charge after stroke: a randomised controlled trial of a person-centered, self-directed, rehabilitation intervention in community stroke survivors. Eur Stroke $J$ 2019.

16 Hays RD, Morales LS. The RAND-36 measure of health-related quality of life. Ann Med 2001;33:350-7.

17 Kauhanen M-L, Korpelainen JT, Hiltunen P, et al. Domains and determinants of quality of life after stroke caused by brain infarction. Arch Phys Med Rehabil 2000;81:1541-6.

18 Bjelland I, Dahl AA, Haug TT, et al. The validity of the hospital anxiety and depression scale. J Psychosom Res 2002;52:69-77.

19 Lemay KR, Tulloch HE, Pipe AL, et al. Establishing the minimal clinically important difference for the hospital anxiety and depression scale in patients with cardiovascular disease. J Cardiopulm Rehabil Prev 2018:1.

20 Bruno A, Akinwuntan AE, Lin C, et al. Simplified modified Rankin scale questionnaire: reproducibility over the telephone and validation with quality of life. Stroke 2011;42:2276-9.

21 Quinn TJ, Lees KR, Hardemark H-G, et al. Initial experience of a digital training resource for modified Rankin scale assessment in clinical trials. Stroke 2007;38:2257-61.

22 Lees KR, Quinn TJ, Dawson J. English program. Available: http:// rankinenglish.trainingcampus.net/

23 Field A. Discovering statistics using IBM SPSS statistics, 2013: 297-321.

24 van Mierlo ML, van Heugten CM, Post MWM, et al. Quality of life during the first two years post stroke: the Restore4Stroke cohort study. Cerebrovasc Dis 2016;41:19-26.

25 Broomfield NM, Quinn TJ, Abdul-Rahim AH, et al. Depression and anxiety symptoms post-stroke/TIA: prevalence and associations in cross-sectional data from a regional stroke Registry. BMC Neurol $2014 ; 14$.

26 Kutlubaev MA, Hackett ML. Part II: predictors of depression after stroke and impact of depression on stroke outcome: an updated systematic review of observational studies. Int J Stroke 2014;9:1026-36.

27 Kim E-S, Kim J-W, Kang H-J, et al. Longitudinal impact of depression on quality of life in stroke patients. Psychiatry Investig 2018;15:141-6.

28 Shi YZ, Xiang YT, Yang Y, et al. Depression after minor stroke: the association with disability and quality of life - a 1-year follow-up study. Int J Geriatr Psychiatry 2016;31:421-7.

29 Haacke C, Althaus A, Spottke A, et al. Long-term outcome after stroke: evaluating health-related quality of life using utility measurements. Stroke 2006;37:193-8.

30 Ayerbe L, Ayis SA, Crichton S, et al. Natural history, predictors and associated outcomes of anxiety up to 10 years after stroke: the South London stroke register. Age Ageing 2014;43:542-7.

31 Jeong B-O, Kang H-J, Bae K-Y, et al. Determinants of quality of life in the acute stage following stroke. Psychiatry Investig 2012;9:127-33

32 Jeon NE, Kwon KM, Kim YH, et al. The factors associated with health-related quality of life in stroke survivors age 40 and older. Ann Rehabil Med 2017;41:743-52.

33 Franzén-Dahlin Åsa, Laska AC. Gender differences in quality of life after stroke and TIA: a cross-sectional survey of out-patients. J Clin Nurs 2012;21:2386-91.

34 Lopez-Espuela F, Zamorano JDP, Ramírez-Moreno JM, et al. Determinants of quality of life in stroke survivors after 6 months, from a comprehensive stroke unit: a longitudinal study. Biol Res Nurs 2015;17:461-8.

35 Gall SL, Tran PL, Martin K, et al. Sex differences in long-term outcomes after stroke: functional outcomes, handicap, and quality of life. Stroke 2012;43:1982-7.

36 Cherepanov D, Palta M, Fryback DG, et al. Gender differences in health-related quality-of-life are partly explained by sociodemographic and socioeconomic variation between adult men and women in the US: evidence from four us nationally representative data sets. Qual Life Res 2010;19:1115-24.

37 Paul SL, Sturm JW, Dewey HM, et al. Long-Term outcome in the North East Melbourne stroke incidence study: predictors of quality of life at 5 years after stroke. Stroke 2005;36:2082-6. 